\title{
Hydrogen sulfide attenuates doxorubicin-induced cardiotoxicity by inhibiting calreticulin expression in $\mathrm{H9c} 2$ cells
}

\author{
MI-HUA LIU ${ }^{1 *}$, YUAN ZHANG $^{2 *}$, XIAO-LONG LIN ${ }^{3}$, JUN HE $^{1}$, TIAN-PING TAN ${ }^{1}$, SHAO-JIAN WU ${ }^{1}$, \\ SHAN YU ${ }^{1}$, LI CHEN ${ }^{1}$, YU-DAN CHEN ${ }^{1}$, HONG-YUN FU ${ }^{1}$, CONG YUAN $^{4}$ and JIAN LI ${ }^{5}$ \\ ${ }^{1}$ Department of Clinical Laboratory, Affiliated Nanhua Hospital, University of South China, Hengyang, Hunan 421001; \\ ${ }^{2}$ Department of Pathology, Mawangdui Hospital, Changsha, Hunan 410016; ${ }^{3}$ Department of Pathology, \\ The Third People's Hospital of Huizhou, Huizhou, Guangdong 516002; ${ }^{4}$ Department of Cardiology, \\ The First Hospital of Changsha, Changsha, Hunan 410005; ${ }^{5}$ Department of Ultrasonic Diagnosis, \\ Boai Hospital of Zhongshan, Zhongshan, Guangdong 528403, P.R. China
}

Received September 24, 2014; Accepted June 11, 2015

DOI: $10.3892 / \mathrm{mmr} .2015 .4020$

\begin{abstract}
Doxorubicin (DOX) is a potent and currently available antitumor therapeutic agent; however, its clinical application is limited by the occurrence of cardiotoxicity. Preliminary evidence indicates that hydrogen sulfide $\left(\mathrm{H}_{2} \mathrm{~S}\right)$ may exert protective effects against DOX cardiotoxicity. Therefore, the aim of the present study was to investigate whether calreticulin (CRT) is involved in the cardioprotection of $\mathrm{H}_{2} \mathrm{~S}$ against DOX-induced cardiotoxicity. DOX was observed to markedly induce injuries, including cytotoxicity and apoptosis, and also enhance the expression level of CRT. Notably, pretreatment of H9c2 cells with sodium hydrosulfide (a donor of $\mathrm{H}_{2} \mathrm{~S}$ ) significantly attenuated the decreased cell viability, the increased apoptosis rate and the increased expression level of CRT in H9c2 cells. In addition, pretreatment of $\mathrm{H} 9 \mathrm{c} 2$ cells with $\mathrm{N}$-acetyl-L-cysteine, a scavenger of reactive oxygen species (ROS) prior to exposure to DOX, markedly decreased the expression of CRT. These results indicate that exogenous $\mathrm{H}_{2} \mathrm{~S}$ attenuates DOX-induced cardiotoxicity by inhibiting CRT expression in H9c2 cardiac cells.
\end{abstract}

Correspondence to: Mr. Mi-Hua Liu, Department of Clinical Laboratory, Affiliated Nanhua Hospital, University of South China, 336 Dongfeng South Road, Hengyang, Hunan 421001, P.R. China E-mail:mihualiu@163.com

Mr. Jian Li, Department of Ultrasonic Diagnosis, Boai Hospital of Zhongshan, Zhongshan, Guangdong 528403, P.R. China

E-mail: 190109588@qq.com

*Contributed equally

Key words: hydrogen sulfide, extracellular signal-regulated kinase $1 / 2$, calreticulin, apoptosis, cardiomyocytes

\section{Introduction}

To date, doxorubicin (DOX) remains one of the most widely administered anticancer therapeutic agents, due to its potent therapeutic affects on a variety of cancer types, including leukemia, lymphoma and breast cancer (1). However, its clinical use is limited by severe toxic side-effects on the heart, which may lead to dilated cardiomyopathy and congestive heart failure (2). Numerous studies have shown that reactive oxygen species (ROS) generation has been implicated in DOX's cardiotoxicity, which ultimately leads to cardiomyocyte apoptosis (3). The signal transduction pathway that links DOX-induced oxidative stress and cardiac injuries is currently a topic of particular interest.

Calreticulin (CRT), a $\mathrm{Ca}^{2+}$-binding molecular chaperone in the endoplasmic reticulum (ER), is vital in cardiac physiology and pathology $(4,5)$. Recently, CRT was identified as a novel embryonic cardiac gene, which is highly expressed in embryonic hearts (6), however, its expression is suppressed after birth (7). Postnatally, elevated levels of CRT expression lead to impaired development of the cardiac conductive system and may be responsible for complete heart block (8). In a study of transgenic mice overexpressing CRT in the heart, the mice developed bradycardia, associated with sinus node dysfunction, complete cardiac block and succumbed due to intractable heart failure (9). Furthermore, overexpression of CRT enhanced apoptosis in myocardial H9c2 cells under conditions of retinoic acid-induced differentiation (10) or oxidative stress (11). These findings indicate that CRT overexpression is a key factor determining cellular susceptibility to oxidative stress-induced apoptosis. Recent studies on H9c2 cells indicate that overexpression of CRT in cardiomyocytes affects the Akt signaling pathway and promotes apoptosis $(10,12)$. However, the biological significance of CRT expression levels in DOX-induced cardiotoxicity currently remains unknown.

Hydrogen sulfide $\left(\mathrm{H}_{2} \mathrm{~S}\right)$, a well-known toxic gas, has been specified as the third gasotransmitter along with nitric oxide and carbon monoxide (13). Accumulating evidence has shown that $\mathrm{H}_{2} \mathrm{~S}$ exerts important physiologic and pathophysiological action in the regulation of cardiovascular function (14). Our 
previous study revealed that increased endogenous $\mathrm{H}_{2} \mathrm{~S}$ generation in the early reperfusion phase is significant in ischemia preconditioning (IPC)-elicited protection in isolated hearts (14). Based on these previous studies, the present study investigates the role of CRT in the protective effects of $\mathrm{H}_{2} \mathrm{~S}$ against DOX-induced cardiomyocyte injuries.

$\mathrm{H} 9 \mathrm{c} 2$ cells were treated with $5 \mu \mathrm{M}$ DOX to establish a chemotherapy-induced cardiotoxicity model (15) and the aim of the present study was to establish whether DOX induces expression of CRT in $\mathrm{H} 9 \mathrm{c} 2$ cells. Furthermore, the role of CRT in the protective effect of $\mathrm{H}_{2} \mathrm{~S}$ against DOX-induced injury in $\mathrm{H} 9 \mathrm{c} 2$ cells was elucidated.

\section{Materials and methods}

Materials. Methylthiazolyl-tetrazolium(MTT),Hoechst33258, DOX, sodium hydrosulfide (NaHS), and N-acetyl-L-cysteine (NAC) were purchased from Sigma-Aldrich (St. Louis, MO, USA). All cell culture medium components were purchased from Thermo Fisher Scientific, Inc. (Waltham, MA, USA) unless otherwise stated. The H9c2 cardiac myocytes were obtained from the Type Culture Collection of the Chinese Academy of Sciences (Shanghai, China) (originally from the American Type Culture Collection, Manassas, VA, USA).

Cell culture. H9c2 cardiac myocytes were cultured in Dulbecco's modified Eagle's medium (DMEM) supplemented with $10 \%$ fetal bovine serum (FBS), $100 \mu \mathrm{g} / \mathrm{ml}$ streptomycin and $100 \mathrm{U} / \mathrm{ml}$ penicillin streptomycin (both Gibco Life Technologies, Carlsbad, CA, USA) in a humidified 5\% $\mathrm{CO}_{2}$ atmosphere at $37^{\circ} \mathrm{C}$. The $\mathrm{H} 9 \mathrm{c} 2$ cardiac myocytes were passaged every two days. $\mathrm{H} 9 \mathrm{c} 2$ cardiac myocytes were seeded at a density of $2 \times 10^{6}$ cells/dish in $100-\mathrm{mm}$ dishes with $10 \%$ fetal calf serum and incubated for $24 \mathrm{~h}$, the culture medium was subsequently changed to $0.5 \%$ FBS DMEM for 24-h starvation.

MTT assay. The MTT assay is a standard method used to assess cell viability. Prior to each experiment, H9c2 cardiac myocytes $(5,000$ cells/well) were seeded in 96-well microtiter plates. Following incubation with NaHS for $30 \mathrm{~min}$, the cells were treated with $5 \mu \mathrm{M}$ DOX for a further $24 \mathrm{~h}$. Subsequently, $10 \mu \mathrm{l}$ MTT solution was added to each well and the plates were incubated for $4 \mathrm{~h}$ at $37^{\circ} \mathrm{C}$ in a $5 \%$ $\mathrm{CO}_{2}$. The absorbance was measured with the SpectraMax 190 Spectrophotometer (Molecular Devices LLC, Sunnyvale, CA, USA) at $470 \mathrm{~nm}$ and used to calculate the relative ratio of cell viability (optical density of treatment group/optical density of control group x100\%). Three independent experiments were performed for each experimental condition.

Assessment of cardiomyocyte cell apoptosis. Apoptosis was analyzed by fluorescence microscopy with the chromatin dye, Hoechst 33258. Following various treatments, the cells were fixed in ice-cold 4\% paraformaldehyde dissolved in phosphate-buffered saline (PBS) at room temperature for $20 \mathrm{~min}$. Non-specific binding was blocked using 5\% normal goat serum in $0.01 \mathrm{M}$ PBS containing $0.3 \%$ Triton X-100. Cells were washed twice with PBS and incubated with $10 \mu \mathrm{g} / \mathrm{ml}$ Hoechst 33258 for $15 \mathrm{~min}$ at room temperature in the dark.
The cells were visualized under a fluorescence microscope (BX50-FLA; Olympus Corporation, Tokyo, Japan). Apoptotic cells exhibited condensed, fractured or distorted nuclei, whereas viable cells displayed normal nuclear size and uniform fluorescence.

Western blot analysis. Cells were homogenized directly into cell lysis buffer (Cell Signaling Technology, Inc., Danvers, MA, USA) and phosphatase inhibitor cocktail (Sigma-Aldrich), and lysates were centrifuged at $12,000 \mathrm{rpm}$ for $10 \mathrm{~min}$ at $4^{\circ} \mathrm{C}$. The protein concentration was determined with the use of a bicinchoninic acid protein assay kit according to the manufacturer's instruction. The extracted proteins were mixed with $5 \%$ sodium dodecyl sulfate (SDS)-PAGE sample buffer, then boiled at $100^{\circ} \mathrm{C}$ for $7 \mathrm{~min}$ and separated by electrophoresis on a $10 \%$ SDS-polyacrylamide gel. Subsequent to electrophoresis, proteins were transferred to polyvinylidene difluoride membranes. The membranes were blocked in Tris-buffered saline with $0.1 \%$ Tween-20 (TBS-T) containing 5\% non-fat dry milk for $2 \mathrm{~h}$ at room temperature with rotation $(20 \mathrm{rpm}$ for $2 \mathrm{~h}$ ). After blocking, the membranes were incubated with the following antibodies: Rabbit anti-cystathionine $\gamma$-lyase (CSE) polyclonal antibody (1:1,000; Cell Signaling Technology, Inc.) and rabbit CRT polyclonal antibody (1:200; Abcam, Cambridge, UK). Then, membranes were incubated in bovine serum albumin overnight at $4^{\circ} \mathrm{C}$. The primary antibody was removed by washing the membranes three times in TBS-T and incubated for $2 \mathrm{~h}$ with the appropriate horseradish peroxidase-conjugated secondary antibodies. Following three washes in TBS-T, the antigen-antibody bands were detected using an Enhanced Chemiluminescence Reagent kit (Beyotime Institute of Biotechnology, Shanghai, China) and quantified using the Quantity One Software Package (Bio-Rad Laboratories, Ltd., Hemel Hempstead, UK).

Statistical analysis. Results are presented as the mean \pm standard error of the mean. Statistical analysis was performed using Student's t-test or analysis of variance with SPSS 13.0 (SPSS Inc., Chicago, IL, USA) and $\mathrm{P}<0.05$ was considered to indicate a statistically significant difference.

\section{Results}

Effects of DOX on the expression of CRT in H9c2 cells. To investigate the effect of DOX on the expression of CRT, H9c2 cells were treated with $5 \mu \mathrm{M}$ DOX for 0 (at the time of treatment), 3, 6, 12 and $24 \mathrm{~h}$. Western blot analysis demonstrated that DOX treatment enhanced the CRT expression levels in a time-dependent manner (Fig. 1).

DOX inhibited the expression of CSE in H9c2 cells. CSE is the major enzyme responsible for endogenous $\mathrm{H}_{2} \mathrm{~S}$ generation in $\mathrm{H} 9 \mathrm{c} 2$ cells (16). Western blot analysis was performed to evaluate whether DOX decreases endogenous $\mathrm{H}_{2} \mathrm{~S}$ production by inhibiting the expression of CSE. Treatment with $5 \mu \mathrm{M}$ DOX for the indicated time periods $(0,3,6,12$ and $24 \mathrm{~h})$ caused a significant downregulation of CSE expression in H9c2 cells (Fig. 2). These data indicate that DOX induced the inhibition of CSE expression in $\mathrm{H} 9 \mathrm{c} 2$ and contributed to the DOX-elicited decrease in endogenous $\mathrm{H}_{2} \mathrm{~S}$ production. 
A

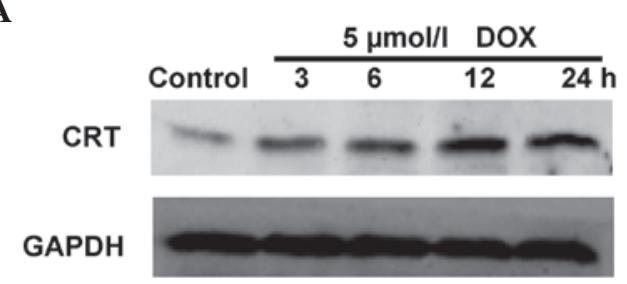

B

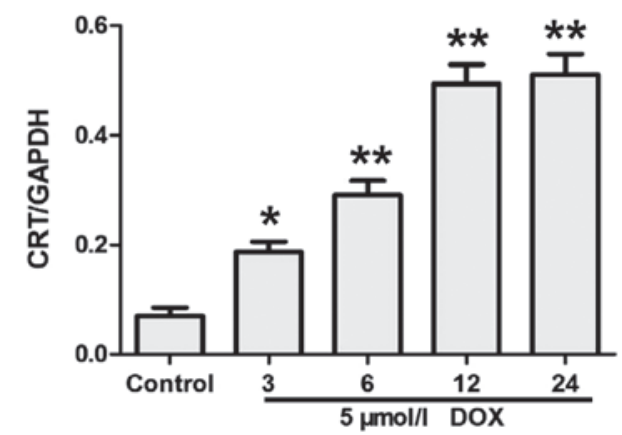

Figure 1. DOX increases the expression of CRT in H9c2 cells. (A) The expression of CRT was analyzed by immunoblotting. (B) Immunoblotting data were quantified by densitometric analysis. Data are presented as the mean \pm standard error of the mean $(n=3)$. ${ }^{*} \mathrm{P}<0.05$ and ${ }^{* * *} \mathrm{P}<0.01$ vs. the control group. CRT, calreticulin; DOX, doxorubicin.

A

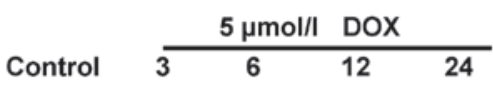

CSE

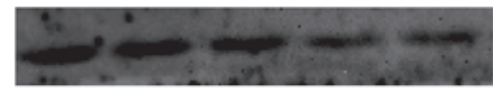

GAPDH

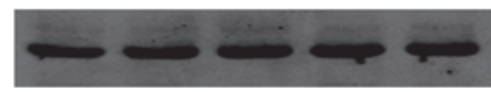

B

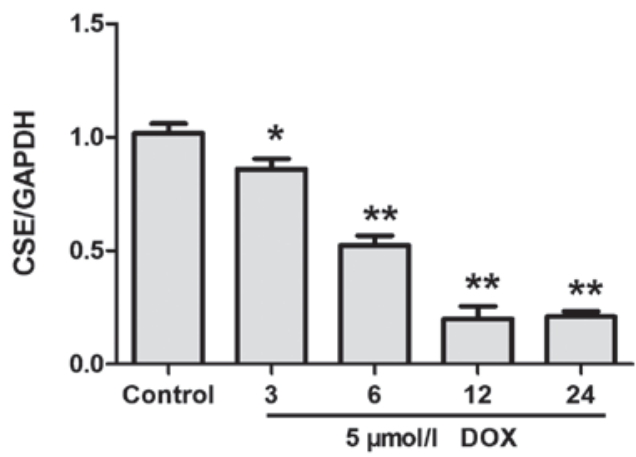

Figure 2. Inhibitory effects of DOX on the expression of CSE in H9c2 cells. (A) Western blot analysis was used to detect the changes in expression of CSE. (B) Densitometric analysis of western blotting. Data are presented as the mean \pm standard error of the mean $(n=3)$. ${ }^{*} \mathrm{P}<0.05$ and ${ }^{* *} \mathrm{P}<0.01$ vs. the control group. CSE, cystathionine $\gamma$-lyase; DOX, doxorubicin.

Exogenous $\mathrm{H}_{2} \mathrm{~S}$ inhibits DOX-induced expression of CRT in $H 9 c 2$ cells. The effect of NaHS on the expressions of CRT induced by DOX was detected to assess whether the cytoprotective effect of $\mathrm{H}_{2} \mathrm{~S}$ against DOX-induced toxicity was associated with the inhibition of CRT in H9c2 cells. The results demonstrated that pretreatment of $\mathrm{H} 9 \mathrm{c} 2$ cells with $100 \mu \mathrm{M} \mathrm{NaHS}$ (a donor of $\mathrm{H}_{2} \mathrm{~S}$ ) for 30 min prior to exposure to $5 \mu \mathrm{mol} / 1 \mathrm{DOX}$ for $24 \mathrm{~h}$ significantly inhibited the DOX-induced
A

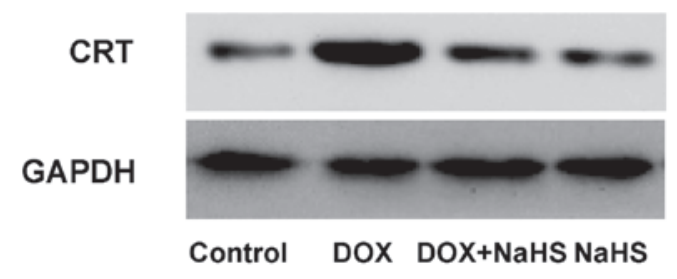

B

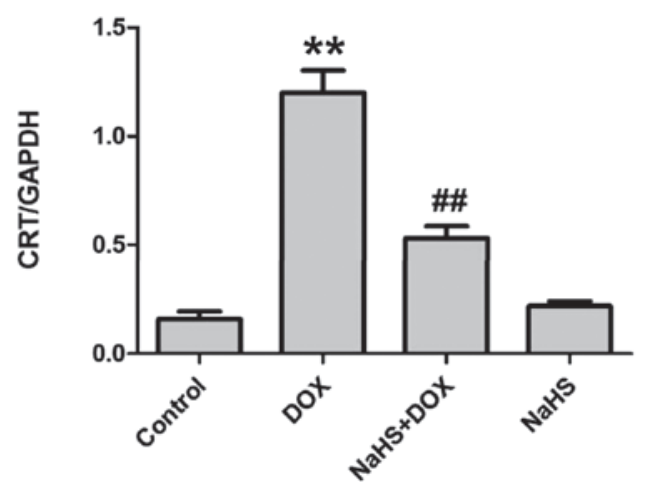

Figure 3. Exogenous hydrogen sulfide attenuated DOX-induced expression of CRT in H9c2 cells. (A) Expression of CRT was assessed by western blotting. (B) The data from western blotting were quantified by densitometric analysis. Data are presented as the mean \pm standard error of the mean $(n=3)$. ${ }^{* *} \mathrm{P}<0.01$ vs. the control group; ${ }^{\# \#} \mathrm{P}<0.01$ vs. the DOX-treated group. CRT, calreticulin; DOX, doxorubicin; NaHS, sodium hydrosulfide.

A

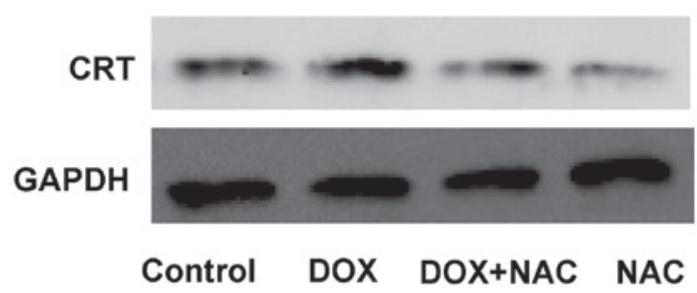

B

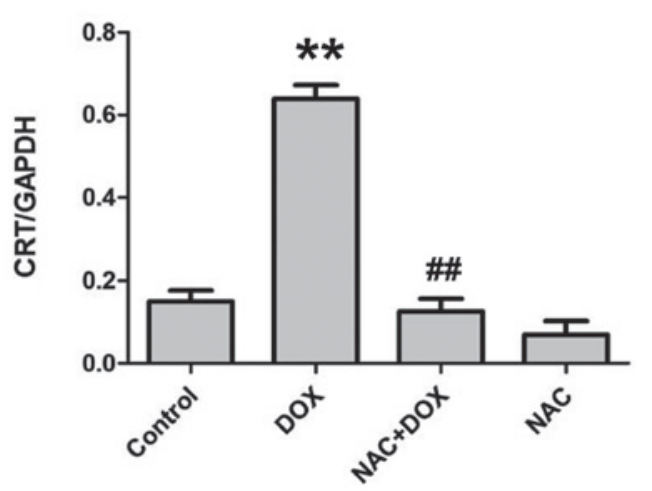

Figure 4. Effect of NAC on DOX-induced expression of CRT in H9c2 cells. (A) CRT expression was analyzed by immunoblotting. (B) Immunoblotting data were quantified by densitometric analysis. Data are presented as the mean \pm standard error of the mean $(n=3) .{ }^{* *} \mathrm{P}<0.01$ vs. the control group; ${ }^{\# \prime} \mathrm{P}<0.01$ vs. the DOX-treated group. CRT, calreticulin; DOX, doxorubicin; NAC, N-acetyl-L-cysteine.

overexpression of CRT (Fig. 3). These data indicate that the cardioprotection of $\mathrm{H}_{2} \mathrm{~S}$ is associated with its inhibitory effect on DOX-induced CRT expression.

NAC suppresses the DOX-induced expression of CRT in $H 9 c 2$ cells. To identify whether the inhibitory effect of NaHS on the 


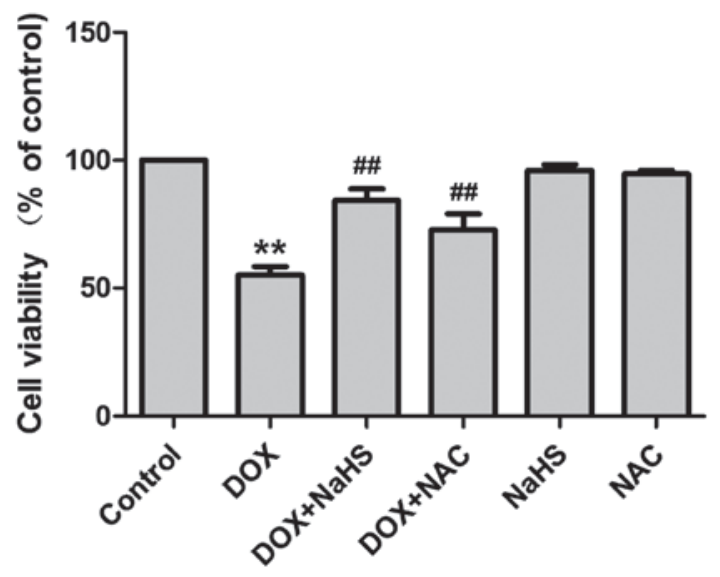

Figure 5. Exogenous hydrogen sulfide and NAC protect H9c2 cells against DOX-induced cytotoxicity. H9c2 cells were treated with $5 \mu \mathrm{mol} / 1 \mathrm{DOX}$ for $24 \mathrm{~h}$, in the absence of, or following pretreatment with $100 \mu \mathrm{M}$ NaHS for $30 \mathrm{~min}$ or NAC for $60 \mathrm{~min}$. Cell viability was measured by methyl thiazolyl tetrazolium assay. Data are presented as the mean \pm standard error of the mean $(\mathrm{n}=3) .{ }^{* *} \mathrm{P}<0.01$ vs. the control group; ${ }^{\# \#} \mathrm{P}<0.01$ vs. the DOX-treated group. DOX, doxorubicin; NaHS, sodium hydrosulfide; NAC, N-acetyl-L-cysteine.

A
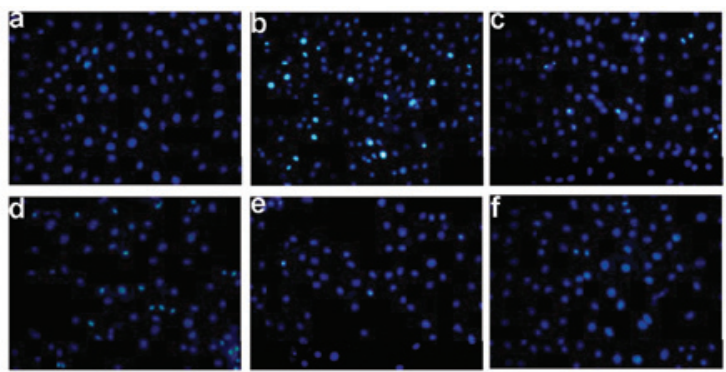

B

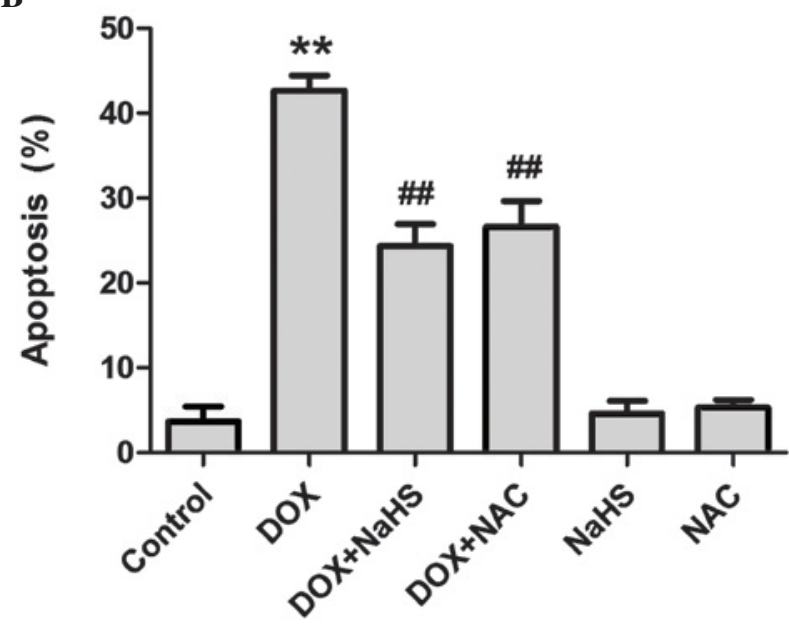

Figure 6. Exogenous hydrogen sulfide and NAC protect $\mathrm{H} 9 \mathrm{c} 2$ cells against DOX-induced apoptosis. (A) Hoechst 33258 nuclear staining followed by fluorescence imaging to observe cell apoptosis: (a) Control group; (b) DOX group; (c) DOX + NaHS group; (d) DOX + NAC group; (e) NaHS group; (f) NAC group. (B) The apoptotic rate was analyzed with a cell counter and ImageJ 1.410 software. Data are presented as the mean \pm standard error of the mean $(\mathrm{n}=3) .{ }^{* *} \mathrm{P}<0.01$, compared with control group; ${ }^{\# \#} \mathrm{P}<0.01$ vs. the DOX-treated group. DOX, doxorubicin; NaHS, sodium hydrosulfide; NAC, $\mathrm{N}$-acetyl-L-cysteine.

DOX-induced increase in expression of CRT is associated with its antioxidation, $\mathrm{H} 9 \mathrm{c} 2$ cells were pretreated with $1,000 \mu \mathrm{M}$ NAC (an ROS scavenger) for $60 \mathrm{~min}$ prior to exposure to $5 \mu \mathrm{M}$
DOX for $24 \mathrm{~h}$. As shown in Fig. 4, similar to the inhibitory effect of NaHS pretreatment, the pretreatment of cells with NAC for 60 min markedly depressed the expression of CRT. The results revealed that the antioxidant effect, resulting from NAC administration, contributed to the inhibitory effect of $\mathrm{H}_{2} \mathrm{~S}$ on the DOX-induced expression of CRT.

Effect of $\mathrm{H}_{2} \mathrm{~S}$ and NAC on DOX-induced cytotoxicity. As presented in Fig. 5, exposure of H9c2 cells to DOX at a dose of $5 \mu \mathrm{M}$ for $24 \mathrm{~h}$ induced marked cytotoxicity, leading to a decrease in cell viability. However, pretreatment of cells with $100 \mu \mathrm{M}$ NaHS for $30 \mathrm{~min}$ prior to exposure to DOX significantly ameliorated the DOX-induced cytotoxicity, as evidenced by an increase in cell viability $(\mathrm{P}<0.01$ compared with the DOX-treated group). Similar to the effect of NaHS, pretreatment with NAC for 60 min significantly attenuated the DOX-induced decrease in cell viability $(\mathrm{P}<0.01$ compared with the DOX-treated group). Neither NaHS nor NAC alone altered cell viability in the $\mathrm{H} 9 \mathrm{c} 2$ cells.

Effect of $\mathrm{H}_{2} \mathrm{~S}$ and NAC on DOX-induced apoptosis. The effects of NaHS and NAC treatment on DOX-induced apoptosis was also observed. As shown in Fig. 6, H9c2 cells treated with $5 \mu \mathrm{M}$ DOX for $24 \mathrm{~h}$ exhibited typical characteristics of apoptosis, including condensation of chromatin, shrinkage of nuclei and apoptotic bodies. However, pretreatment of cells with $100 \mu \mathrm{M}$ NaHS for 30 min prior to DOX exposure markedly decreased the DOX-induced increase in cell number, as well as decreasing the nuclear condensation and fragmentation. In addition, $\mathrm{H} 9 \mathrm{c} 2$ cells were preconditioned with a common ROS scavenger, NAC $(1,000 \mu \mathrm{M})$ prior to DOX treatment. The results indicated that pretreatment of cells with NAC significantly attenuated DOX-induced H9c2 cell apoptosis. NaHS or NAC alone did not markedly alter the cell morphology or the percentage of apoptotic $\mathrm{H} 9 \mathrm{c} 2$ cells. These findings suggest that an antioxidant effect participates in the inhibitory effect of $\mathrm{H}_{2} \mathrm{~S}$ on the DOX-induced apoptosis of $\mathrm{H} 9 \mathrm{c} 2$ cells.

\section{Discussion}

Numerous studies have revealed that the major molecular mechanism involved in DOX-induced cardiac toxicity is free radical-induced oxidative stress and cardiomyocyte death, as a result of apoptosis and necrosis. Consistent with previous studies $(17,18)$, the present study observed that exposure of H9c2 cells to DOX markedly induced cellular injury, including decreased cell viability, as well as increased cell apoptosis and expression of CRT.

Previously, the cardioprotective effects of $\mathrm{H}_{2} \mathrm{~S}$ have been demonstrated in animal models of disease (19). $\mathrm{H}_{2} \mathrm{~S}$ infusion significantly reduces myocardial infract size and improves regional left ventricularfunction, as well as endothelium-dependent and -independent microvascular reactivity in a porcine model of myocardial ischemia-reperfusion (20). Furthermore, $\mathrm{H}_{2} \mathrm{~S}$ attenuates myocardial necrosis and apoptosis (21). In addition, endogenous $\mathrm{H}_{2} \mathrm{~S}$ is associated with the cardioprotection that results from metabolic inhibition preconditioning in rat ventricular myocytes (22). Inhibition of endogenous $\mathrm{H}_{2} \mathrm{~S}$ generation, by its synthesis inhibitor (DL-propargylglycine), has been shown to block the protective effect of IPC in isolated 
hearts, as well as in isolated cardiac myocytes (23). In the present study, $\mathrm{H} 9 \mathrm{c} 2$ cells were used to elucidate the effect of DOX on endogenous $\mathrm{H}_{2} \mathrm{~S}$ generation. Exposure of $\mathrm{H} 9 \mathrm{c} 2$ cells to DOX resulted in a significant decrease in $\mathrm{H}_{2} \mathrm{~S}$ generation.

CRT is a major ER protein that is significant in cardiac development and pathology (24). Various reviews have revealed that CRT is highly expressed in embryonic hearts, but not in mature hearts, and may be an early cardiac gene product (25). Mice with a targeted disruption of the CRT gene succumb in utero exhibiting decreased ventricular cell mass due to increased apoptosis of cardiac myocytes (26). In addition, studies with CRT-deficient cells suggest that CRT participates in apoptosis (27). In the CRT transgenic heart, CRT-dependent cardiac block involves damage to L-type $\mathrm{Ca}^{2+}$ channels, and gap junction connexin-40 and -43 , due to defective regulation of $\mathrm{Ca}^{2+}$ homeostasis (8). Overexpression of CRT suppresses Akt signaling and causes differentiation-induced apoptosis in H9c2 cells (10). In the present study, the results showed that the expression of CRT was increased following DOX treatment, and exogenous $\mathrm{H}_{2} \mathrm{~S}$ preconditioning was demonstrated to suppress CRT expression while markedly attenuating DOX-induced apoptosis.

Increasing evidence indicates that ROS are significant in the pathogenesis of cardiac failure (28). Furthermore, antioxidants have been shown to exert protective and beneficial effects against heart failure (29). Oxidative stress is a primary mechanism by which DOX induces cardiomyocyte injury. Notably, the present study demonstrated that oxidative stress was involved in DOX-induced cell injury and established whether DOX activation of CRT is due to the induction of ROS. Pretreatment of H9c2 cells with NAC (a ROS scavenger) was shown to significantly attenuate DOX-induced expression of CRT. Thus, the results of the present study support the hypothesis that DOX induction of ROS activates CRT, which mediates DOX-induced injury in H9c2 cells.

In conclusion, the current study identified that $\mathrm{H}_{2} \mathrm{~S}$ inhibits DOX-induced apoptosis in H9c2 cells, which may involve inhibition of ROS-mediated CRT expression. Therefore, the present study has elucidated the mechanisms of $\mathrm{H}_{2} \mathrm{~S}$-mediated anti-apoptosis in cardiomyocytes and provided evidence for identifying $\mathrm{H}_{2} \mathrm{~S}$ as a candidate for application in the treatment of cardiovascular diseases.

\section{Acknowledgements}

The present study was supported by grants from the Medical Scientific Research Funds of Guangdong province (grant no. A2014810) and the Graduate Student Research Innovation Project of Hunan province (grant no. CX2013B397).

\section{References}

1. Menna P, Recalcati S, Cairo G and Minotti G: An introduction to the metabolic determinants of anthracycline cardiotoxicity. Cardiovasc Toxicol 7: 80-85, 2007.

2. Lipshultz SE, Karnik R, Sambatakos P, Franco VI, Ross SW and Miller TL: Anthracycline-related cardiotoxicity in childhood cancer survivors. Curr Opin Cardiol 29: 103-112, 2014.

3. Spallarossa P, Garibaldi S, Altieri P, Fabbi P, Manca V, Nasti S, Rossettin P, Ghigliotti G, Ballestrero A, Patrone F, et al: Carvedilol prevents doxorubicin-induced free radical release and apoptosis in cardiomyocytes in vitro. J Mol Cell Cardiol 37: 837-846, 2004
4. Raturi A, Ortiz-Sandoval C and Simmen T: Redox dependence of endoplasmic reticulum (ER) $\mathrm{Ca}^{2+}$ signaling. Histol Histopathol 29: 543-552, 2014.

5. Ma J and Pan Z: Retrograde activation of store-operated calcium channel. Cell Calcium 33: 375-384, 2003.

6. Mesaeli N, Nakamura K,Zvaritch E,Dickie P,Dziak E, Krause KH, Opas M, MacLennan DH and Michalak M: Calreticulin is essential for cardiac development. J Cell Biol 144: 857-868, 1999.

7. Milan D, Griffith J, Su M, Price ER and McKeon F: The latch region of calcineurin B is involved in both immunosuppressant-immunophilin complex docking and phosphatase activation. Cell 79: 437-447, 1994.

8. Nakamura K, Robertson M, Liu G, Dickie P, Guo JQ, Duff HJ, Opas M, Kavanagh K and Michalak M: Complete heart block and sudden death in mice overexpressing calreticulin. J Clin Invest 107: 1245-1253, 2001.

9. Lynch JM, Chilibeck K, Qui Y and Michalak M: Assembling pieces of the cardiac puzzle; calreticulin and calcium-dependent pathways in cardiac development, health and disease. Trends Cardiovasc Med 16: 65-69, 2006.

10. Kageyama K, Ihara Y, Goto S, Urata Y, Toda G, Yano K and Kondo T: Overexpression of calreticulin modulates protein kinase $\mathrm{B} /$ Akt signaling to promote apoptosis during cardiac differentiation of cardiomyoblast H9c2 cells. J Biol Chem 277: 19255-19264, 2002.

11. Ihara Y, Urata $Y$, Goto $S$ and Kondo T: Role of calreticulin in the sensitivity of myocardiac H9c2 cells to oxidative stress caused by hydrogen peroxide. Am J Physiol Cell Physiol 290: C208-C221, 2006.

12. Konishi M, Haraguchi G, Ohigashi H, Ishihara T, Saito K, Nakano $\mathrm{Y}$ and Isobe $\mathrm{M}$ : Adiponectin protects against doxorubicin-induced cardiomyopathy by anti-apoptotic effects through AMPK up-regulation. Cardiovasc Res 89: 309-319, 2011.

13. Zhang Y, Tang ZH, Ren Z, Qu SL, Liu MH, Liu LS and Jiang ZS: Hydrogen sulfide, the next potent preventive and therapeutic agent in aging and age-associated diseases. Mol Cell Biol 33: 1104-1113, 2013.

14. Huang YE, Tang ZH, Xie W, Shen XT, Liu MH, Peng XP, Zhao ZZ, Nie DB, Liu LS and Jiang ZS: Endogenous hydrogen sulfide mediates the cardioprotection induced by ischemic postconditioning in the early reperfusion phase. Exp Ther Med 4: $1117-1123,2012$.

15. Guo R, Lin J, Xu W, Shen N, Mo L, Zhang C and Feng J: Hydrogen sulfide attenuates doxorubicin-induced cardiotoxicity by inhibition of the p38 MAPK pathway in H9c2 cells. Int J Mol Med 31: 644-650, 2013.

16. Kimura H: Hydrogen sulfide: Its production, release and functions. Amino Acids 41: 113-121, 2011.

17. Wang X, Wang XL, Chen HL, Wu D, Chen JX, Wang XX, Li RL, He JH, Mo L, Cen X, et al: Ghrelin inhibits doxorubicin cardiotoxicity by inhibiting excessive autophagy through AMPK and p38-MAPK. Biochem Pharmacol 88: 334-350, 2014.

18. Guo R, Wu K, Chen J, Mo L, Hua X, Zheng D, Chen P, Chen G, $\mathrm{Xu} \mathrm{W}$ and Feng J: Exogenous hydrogen sulfide protects against doxorubicin-induced inflammation and cytotoxicity by inhibiting p38MAPK/NFkB pathway in H9c2 cardiac cells. Cell Physiol Biochem 32: 1668-1680, 2013.

19. Ji Y, Pang QF, Xu G, Wang L, Wang JK and Zeng YM: Exogenous hydrogen sulfide postconditioning protects isolated rat hearts against ischemia-reperfusion injury. Eur J Pharmacol 587: 1-7, 2008.

20. Osipov RM, Robich MP, Feng J, Liu Y, Clements RT, Glazer HP, Sodha NR, Szabo C, Bianchi C and Sellke FW: Effect of hydrogen sulfide in a porcine model of myocardial ischemia-reperfusion: Comparison of different administration regimens and characterization of the cellular mechanisms of protection. J Cardiovasc Pharmacol 54: 287-297, 2009.

21. Sodha NR, Clements RT, Feng J, Liu Y, Bianchi C, Horvath EM, Szabo C and Sellke FW: The effects of therapeutic sulfide on myocardial apoptosis in response to ischemia-reperfusion injury. Eur J Cardiothorac Surg 33: 906-913, 2008.

22. Pan TT, Feng ZN, Lee SW, Moore PK and Bian JS: Endogenous hydrogen sulfide contributes to the cardioprotection by metabolic inhibition preconditioning in the rat ventricular myocytes. J Mol Cell Cardiol 40: 119-130, 2006.

23. Bian JS, Yong QC, Pan TT, Feng ZN, Ali MY, Zhou S and Moore PK: Role of hydrogen sulfide in the cardioprotection caused by ischemic preconditioning in the rat heart and cardiac myocytes. J Pharmacol Exp Ther 316: 670-678, 2006.

24. Michalak M, Lynch J, Groenendyk J, Guo L, Robert Parker JM and Opas M: Calreticulin in cardiac development and pathology. Biochim Biophys Acta 1600: 32-37, 2002. 
25. Coe $\mathrm{H}$ and Michalak M: Calcium binding chaperones of the endoplasmic reticulum. Gen Physiol Biophys 28: F96-F103, 2009.

26. Rauch F, Prud'homme J, Arabian A, Dedhar S and St-Arnaud R: Heart, brain and body wall defects in mice lacking calreticulin. Exp Cell Res 256: 105-111, 2000.

27. Nakamura K, Bossy-Wetzel E, Burns K, Fadel MP, Lozyk M, Goping IS, Opas M, Bleackley RC, Green DR and Michalak M: Changes in endoplasmic reticulum luminal environment affect cell sensitivity to apoptosis. J Cell Biol 150: 731-740, 2000.
28. Schwarzer M, Osterholt M, Lunkenbein A, Schrepper A, Amorim P and Doenst T: Mitochondrial reactive oxygen species production and respiratory complex activity in rats with pressure overload-induced heart failure. J Physiol 592: 3767-3782, 2014.

29. Matsushima S, Ide T, Yamato M, Matsusaka H, Hattori $F$, Ikeuchi M, Kubota T, Sunagawa K, Hasegawa Y, Kurihara T, et al: Overexpression of mitochondrial peroxiredoxin-3 prevents left ventricular remodeling and failure after myocardial infarction in mice. Circulation 113: 1779-1786, 2006. 